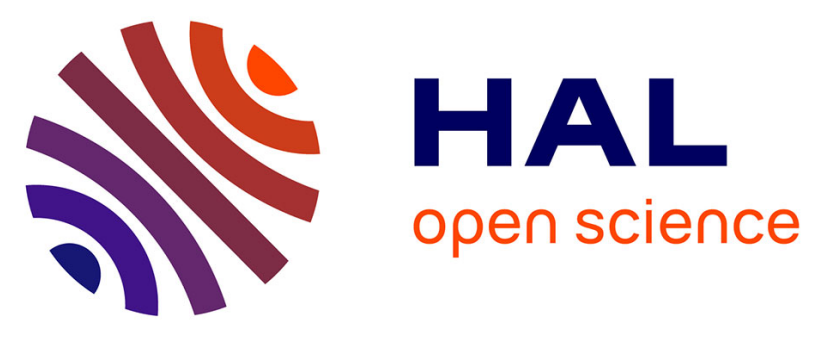

\title{
Effective ion mobility in anion exchange ionomers: Relations with hydration, porosity, tortuosity, and percolation
}

\author{
Philippe Knauth, L. Pasquini, R. Narducci, E. Sgreccia, R.-A \\ Becerra-Arciniegas, M. L Di Vona
}

\section{To cite this version:}

Philippe Knauth, L. Pasquini, R. Narducci, E. Sgreccia, R.-A Becerra-Arciniegas, et al.. Effective ion mobility in anion exchange ionomers: Relations with hydration, porosity, tortuosity, and percolation. Journal of Membrane Science, 2021, 617, pp.118622. 10.1016/j.memsci.2020.118622 . hal-03162015

\section{HAL Id: hal-03162015 \\ https://hal-amu.archives-ouvertes.fr/hal-03162015}

Submitted on 31 Mar 2021

HAL is a multi-disciplinary open access archive for the deposit and dissemination of scientific research documents, whether they are published or not. The documents may come from teaching and research institutions in France or abroad, or from public or private research centers.
L'archive ouverte pluridisciplinaire HAL, est destinée au dépôt et à la diffusion de documents scientifiques de niveau recherche, publiés ou non, émanant des établissements d'enseignement et de recherche français ou étrangers, des laboratoires publics ou privés.

\section{(ㅇ)(1) $\$$}

Distributed under a Creative Commons Attribution - NonCommercial - NoDerivatives 44.0 
Effective ion mobility in anion exchange ionomers: relations with hydration, porosity, tortuosity, and percolation

P. Knauth ${ }^{1}$, L. Pasquini ${ }^{1}$, R. Narducci ${ }^{2}$, E. Sgreccia ${ }^{2}$, R.-A. Becerra-Arciniegas ${ }^{1,2}$, M. L. Di Vona $^{2}$

1 Aix Marseille Univ, CNRS, MADIREL (UMR 7246) and International Associated Laboratory: Ionomer Materials for Energy, Campus St Jérôme, 13013 Marseille, France

${ }^{2}$ University of Rome Tor Vergata, Dep. Industrial Engineering, and International Associated Laboratory: Ionomer Materials for Energy, 00133 Roma, Italy

Keywords: Anion exchange membranes; Ionic conductivity; Polysulfone; Poly(2,6-dimethyl1,4-phenylene)oxide; Ion pairs 


\section{ABSTRACT}

The effective mobility of hydroxide, chloride and fluoride ions is reported in various anion exchange membranes (AEM) with a backbone of polysulfone (PSU) or poly(2,6-dimethyl1,4-phenylene)oxide (PPO). The concentration dependence of the effective mobility is used to derive the porosity $(\pi)$, tortuosity $(\tau)$, and percolation thresholds and to plot the ionic conductivity $v s$ the hydration number. Semi-logarithmic plots of the effective ion mobility $u(i)$ $v s$ the square root of concentration $\sqrt{ } c(i)$ for hydroxide, fluoride and chloride ions in various PSU- and PPO-based ionomers at 25 and $60{ }^{\circ} \mathrm{C}$ show linear relations, from which the ratio $\pi / \tau$ can be determined. This existence of linear $u(i)=f(\sqrt{c}(i))$ plots is related to the very particular boundary conditions experienced by mobile ions, migrating in close vicinity to the immobile grafted counter-ions placed at the interfaces between polymer domains and electrolyte solution. The $\pi / \tau$ values for PSU-QA (0.29) and PPO-QA (0.38) are consistent with a relatively low hydrophilic-hydrophobic nanophase separation, which leads to channels with low diameter and high tortuosity. The tortuosity determined from a Bruggeman-type relation is 1.9 for PSU-QA and 1.6 for PPO-QA. The percolation thresholds $\phi_{\mathrm{H}_{2} \mathrm{O}, p}$, determined from the universal percolation equation near and above $\phi_{\mathrm{H}_{2} O, p}$, are at a water volume fraction of 0.07 for PSU-TMA and 0.03 for PPO-QA indicating that these AEM have a two-dimensional structure of the hydrated domains. The prefactor, which should represent a good indication as to the maximum achievable ionic conductivity, is slightly below 100 $\mathrm{mS} / \mathrm{cm}$ for both PSU-TMA and PPO-based ionomers. Plots of experimental and computed hydroxide and chloride ion conductivities as function of the hydration number $(\lambda)$ show a maximum ionic conductivity for a value of the hydration number around 60, corresponding to optimal hydration conditions. At $\lambda=100$, the ratio of conductivity between PSU-QA $\left(\mathrm{OH}^{-}\right.$ form) and PPO-QA ( $\mathrm{Cl}^{-}$form) indicates that the degree of dissociation of ion pairs is about $30 \%$ lower for hydroxide than for chloride ions, which is consistent with the effective ionic radii of $\mathrm{Cl}^{-}$and $\mathrm{OH}^{-}$. 


\section{Introduction}

The ionic conductivity of ion exchange membranes is a critical property for their application as separators in various electrochemical energy technologies, such as fuel cells, electrolysers, or redox flow batteries [1-4]. A low ion conductivity increases the area specific resistance of the devices and the Ohmic drop of the electrochemical cell and reduces the energy conversion efficiency by heat production $[5,6]$.

Generally, the ionic conductivity is the sum of the partial conductivities of various ions that depend on three factors: the charge of the ion (equal to the Faraday constant $F$ for molar quantities and a singly charged ion), the ion concentration and the ion mobility. The case of ion exchange polymers is peculiar, because only one type of ion is mobile in the internal electrolytic solution, whereas the counterions are grafted on the polymer backbone and immobile [7-9]. The ion concentration can be modified by a change of the ion exchange capacity (IEC) of the ionomer and/or a change of its hydration [10-12].

The mobility of a single monovalent ion $u(i)$ is defined according to equation 1 by the ionic conductivity $\sigma(i)$ (expressed in $\mathrm{mS} / \mathrm{cm}$ ) and the ion concentration $c(i)$ (expressed in $\mathrm{mol} / \mathrm{L})$ :

$u(i)=\frac{\sigma(i)}{F \cdot c(i)}$

The ion mobility is a complex parameter in an ionomer, given that it reflects the conditions of ionic motion in the restricted area of nanometric ion conduction channels present in the hydrated ionomers, but also the particular electrostatic conditions, where the mobile ions migrate inside channels with immobile counterions grafted on the channel walls [13-15]. This situation reduces the ion mobility by electrostatic interactions. Furthermore, the ionic transport depends on the percolation of the hydrated channels and their tortuosity [16, 17]. The percolation threshold is reached when the hydrated clusters become interconnected and long-range ionic conduction is possible [18]. The cross-section available for ionic conduction is proportional to the effective size of the hydrated channels; it is only a fraction of the total cross-sectional area of the ionomer, expressed phenomenologically by the "porosity" $\pi(0<\pi$ < 1) [19-21]. Moreover, not all pores have the same transport efficiency: the "tortuosity" $\tau$ is also a phenomenological parameter, which describes the complex interconnected pore network with irregular shapes and cross sections $(\tau>1)[17] .1 / \tau$ is the fraction of pore volume having the same efficiency for transport as the bulk electrolyte [16]. The percolation threshold, porosity and tortuosity are a function of the nanophase separation, which is 
associated to the hydrophilicity of the ionic groups and the hydrophobicity of the polymer backbone [22]. Phase-separated morphologies are also related to the temperature and the solvent-polymer and polymer-polymer interactions, described by the Flory-Huggins theory [23].

Various authors have investigated the effective ion mobility dependence on the ion concentration for proton-conducting ionomers [10, 11, 22, 24-29]. We have previously reported the proton mobility dependence on concentration in various sulfonated aromatic polymers (SAP) and perfluorinated sulfonic acid (PFSA) polymers [30-33] and deduced percolation thresholds and tortuosity values [30, 31, 34].

For anion exchange membranes (AEM), the groups of Kreuer [35], Dekel [36], Benziger [37] and Hickner [36, 38] reported anion conductivity data and discussed their relevance. Paddison and coworkers published mesoscale simulations of AEM [39]. Wu et al. discussed the hydroxide ion mobility in poly(ether ether ketone) based AEM [37,40]. In the case of AEM, the dissociation of ion pairs [41] is incomplete, reminiscent of the so-called "Manning condensation" in polyelectrolytes [42].

In this paper, we report the effective mobility of hydroxide, chloride and fluoride ions in various ionomers with a backbone of polysulfone (PSU) or poly(2,6-dimethyl-1,4phenylene)oxide (PPO) and quaternary ammonium (QA) groups. The concentration dependence of the effective mobility is applied to derive the tortuosity and percolation parameters and to establish the relation between conductivity and hydration number. The relevance of these data for practical applications of AEM as ion-conducting separators in electrochemical devices is also discussed.

\section{Experimental}

\subsection{Products}

PSU $(\mathrm{MW}=55500 \mathrm{~g} / \mathrm{mol})$ was purchased from Solvay. PPO $(\mathrm{MW}=50000 \mathrm{~g} / \mathrm{mol})$, 1,5,7-triazabicyclo[4.4.0]dec-5-ene (TBD) trimethylamine (TMA, 4.2 M in ethanol), 1,4diazabicyclo[2.2.2] octane (DABCO), paraformaldehyde $\left(\left(\mathrm{CH}_{2} \mathrm{O}\right)_{n}\right)$, trimethylchlorosilane $\left(\mathrm{Me}_{3} \mathrm{SiCl}\right), \mathrm{SnCl}_{4}$, 1,4-dibromobutane, dimethylsulfoxide (DMSO), and N-methyl-2pyrrolidone (NMP) and all other chemicals were reagent-grade and purchased from SigmaAldrich. 


\subsection{Ionomer synthesis}

The synthesis of the various ionomers was described in the following references: PSUTMA and PSU-DABCO [43], PPO-DABCO with long side chain [44]. In short, PSU-TMA and PSU-DABCO were prepared by the chloromethylation route. Different degrees of chloromethylation were obtained varying the reaction time. Chloromethylated PSU samples (PSU-CH $\mathrm{CH}_{2} \mathrm{Cl}$ ) reacted with TMA and DABCO via nucleophilic substitution (quaternization). PPO-DABCO with long side-chain was prepared by benzyl bromination followed by quaternization. Cross-linked AEM (XL-AEM) were synthetized using 5\% of chlorosulfonated poly(ether ether ketone) (PEEK-SO $\left.{ }_{2} \mathrm{Cl}\right)$ as cross-linker [43].

PPO-DABCO was prepared by the chloromethylation route using the following ratio of reagents PPO: $\mathrm{Me}_{3} \mathrm{SiCl}:\left(\mathrm{CH}_{2} \mathrm{O}\right)_{\mathrm{n}}: \mathrm{SnCl}_{4}=1: 3: 3: 0.05$. Before the use, chloroform was washed with water to remove ethanol and dried on molecular sieves ( $3 \AA$ ). All the steps were carried out under nitrogen in anhydrous conditions. PPO (41.8 meq) was dissolved in $250 \mathrm{~mL}$ of $\mathrm{CHCl}_{3}$ at $\mathrm{RT}$, then the temperature was increased to $45^{\circ} \mathrm{C}$. At the same time $\mathrm{Me}_{3} \mathrm{SiCl}$, paraformaldehyde, and $\mathrm{SnCl}_{4}$ were mixed and heated to $45^{\circ} \mathrm{C}$. After $1 \mathrm{~h}$, a clear solution was obtained. This solution was quickly added to the solution of PPO and the reaction performed at $45{ }^{\circ} \mathrm{C}$ for a time in the range $8-17 \mathrm{~h}$ in order to obtain different degrees of chloromethylation. After this time, the temperature was reduced to $\mathrm{RT}$ and $150 \mathrm{~mL}$ of $\mathrm{CH}_{3} \mathrm{OH}$ added until complete precipitation. The PPO- $\mathrm{CH}_{2} \mathrm{Cl}$ was washed with $\mathrm{CH}_{3} \mathrm{OH}$ and dried in the oven at $60^{\circ} \mathrm{C}$ for $48 \mathrm{~h}$ [45].

The quaternization was carried out in NMP for $72 \mathrm{~h}$ at $70{ }^{\circ} \mathrm{C}$ with a ratio between functional groups of PPO- $\mathrm{CH}_{2} \mathrm{Cl}$ and DABCO 1:1.4. After this time, the solution was reduced to a third under low pressure at $80{ }^{\circ} \mathrm{C}$ and directly used for the casting procedure. The ion exchange capacity (see Table 1) was measured by Mohr titration [44].

\subsection{Composite AEM}

The ionomer composites (see Table 1) were prepared using $\mathrm{TiO}_{2}$ functionalized with poly(methylhydrosiloxane) [46] or layered double hydroxides (LDH) as fillers. The synthesis of $\mathrm{Mg} / \mathrm{Al} \mathrm{LDH}$ was described in reference [47].

\subsection{Membrane preparation}

The membranes were generally prepared by dissolution of the ionomers in NMP, typically $250 \mathrm{mg}$ per $20 \mathrm{~mL}$ of solvent, and casting at $100{ }^{\circ} \mathrm{C}$ before drying in an oven at 90 $100{ }^{\circ} \mathrm{C}$ during $48 \mathrm{~h}$. 
For composite AEM, the nanometric inorganic filler was added to the ionomer solution before casting (between 5 and $30 \mathrm{wt} \%$ ) and sometimes DMSO was preferred to NMP to assure a better homogeneity of the samples. The detailed procedures for composites can be found in the following references: PSU-DABCO-TiO 2 [46], PSU-TMA-LDH [47] and PSUDABCO-LDH [47, 48]. PPO-DABCO-LDH was obtained by adding $30 \mathrm{wt} \%$ of LDH to 20 $\mathrm{mL}$ of a $0.05 \mathrm{M}$ solution of PPO-DABCO in NMP. The mixture was evaporated to a half of the initial volume during vigorous stirring and the viscous solution was cast onto a Petri dish and heated in an oven at $100{ }^{\circ} \mathrm{C}$ during $48 \mathrm{~h}$.

\subsection{Determination of the IEC}

The IEC (meq/g) is expressed in milliequivalents of ionic groups $n$ per mass of dry polymer $m_{d r y}$ :

$I E C=\frac{n}{m_{d r y}}$

The ion exchange capacity was determined by acid-base titration or by Mohr titration. For the latter, the ionomer was first ion-exchanged in a $1 \mathrm{M} \mathrm{NaCl}$ solution during $24 \mathrm{~h}$ and carefully washed in deionized water during $24 \mathrm{~h}$. The polymer dried in a desiccator during $48 \mathrm{~h}$ was immersed in $\mathrm{Na}_{2} \mathrm{SO}_{4}$ solution and the exchanged $\mathrm{Cl}^{-}$ions were titrated with $0.1 \mathrm{M} \mathrm{AgNO}_{3}$ solution. $1 \mathrm{~mL}$ of $0.25 \mathrm{M} \mathrm{K}_{2} \mathrm{CrO}_{4}$ indicator solution was added prior to the titration. At the equivalence point, a red-brown precipitate of $\mathrm{Ag}_{2} \mathrm{CrO}_{4}$ appeared.

\subsection{Water uptake measurements}

The water uptake (WU) is determined from the masses of dry and wet polymer $\left(m_{w e t}\right)$; it is related to the volumes of water and dry polymer via the dry polymer density $\rho_{d r y}$ :

$$
W U=\frac{m_{w e t}-m_{d r y}}{m_{d r y}}=\frac{m_{H 2 O}+m_{d r y}-m_{d r y}}{m_{d r y}}=\frac{m_{H 2 O}}{m_{d r y}}=\frac{V_{H 2 O}}{V_{d r y} \rho_{d r y}}
$$

The densities of the electrolytic solutions are approximated as $1 \mathrm{~g} / \mathrm{cm}^{3}$. Experimental values determined in Nafion are near 1 and the concentration dependence of the electrolyte density is small [49]. We assume that all water molecules reside near ionic groups for thermodynamic affinity reasons (in agreement with the definition of the hydration number) and that the concentration of the internal electrolytic solution is homogeneous throughout the membrane. Combining equations 2 and 3, one obtains:

$W U=\frac{V_{\mathrm{H}_{2} \mathrm{O}} \cdot I E C}{n}$ 
The hydration number, which is the number of water molecules per ionic group, is defined as:

$\lambda=\frac{1000 \cdot W U}{I E C \cdot M\left(H_{2} O\right)}$

$\mathrm{M}\left(\mathrm{H}_{2} \mathrm{O}\right)$ is the molar mass of water.

The measurements were made on ionomers in hydroxide, chloride or fluoride forms. The samples were obtained by ion exchange in $1 \mathrm{M}$ solutions of $\mathrm{NaOH}$ (under nitrogen), $\mathrm{NaCl}$ or $\mathrm{NH}_{4} \mathrm{~F}$ during $24 \mathrm{~h}$. After the ion exchange, the samples were carefully washed in deionized and decarbonated water during $24 \mathrm{~h}$ to remove any excess of electrolyte. The hydroxide forms were analyzed immediately or stored in absence of $\mathrm{CO}_{2}$ to avoid carbonation issues. The mass of wet samples $\left(m_{w e t}\right)$ was determined after immersion during $24 \mathrm{~h}$ in deionized water and wiping the sample surface with absorbing paper. The mass of dry samples $\left(m_{d r y}\right)$ was measured after storing them over $\mathrm{P}_{2} \mathrm{O}_{5}$ in a desiccator during $48 \mathrm{~h}$.

\subsection{Ion conductivity measurements}

AEM samples in hydroxide, chloride, or fluoride forms were made as described above. The fully humidified membranes were immediately placed in Swagelok holders with stainless steel electrodes (through-plane configuration). Electrochemical impedance spectroscopy measurements were performed using a Biologic VSP-300 apparatus. The applied a.c. voltage was $20 \mathrm{mV}$ and the frequency range $1 \mathrm{~Hz}-6 \mathrm{MHz}$. The impedance spectra were interpreted by non-linear least-square fitting using a classical Randles circuit $\left(\mathrm{R}_{1}-\mathrm{R}_{2} / / \mathrm{CPE}\right)$ or a series of two parallel circuits containing a resistance and a constant phase element $\left(\mathrm{R}_{1} / / \mathrm{CPE}_{1}-\mathrm{R}_{2} / / \mathrm{CPE}_{2}\right)$. The ionic conductivity at partial humidification $(65 \leq \mathrm{RH} / \% \leq 95)$ was measured with inplane configuration using the apparatus described in reference [47].

\section{Results}

The chemical formulas of PSU-TMA, PSU-DABCO, PPO-DABCO, and PPODABCO with long side-chain are shown in Figure 1.

Table 1 presents the experimental results for IEC, WU and ionic conductivity for the various investigated AEM.

Table 2 shows the IEC, WU and ionic conductivity data of PSU-TMA and PSUDABCO as well as composites with $\mathrm{LDH}$ at $60{ }^{\circ} \mathrm{C}$ and 95,80 or $65 \% \mathrm{RH}$.

The values of WU (in \%) must be divided by 100 in all equations. 
a)

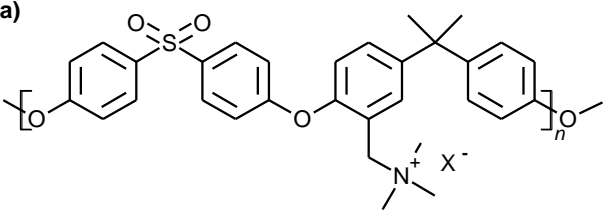

PSU-TMA

c)

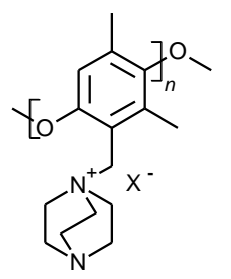

PPO-DABCO b)

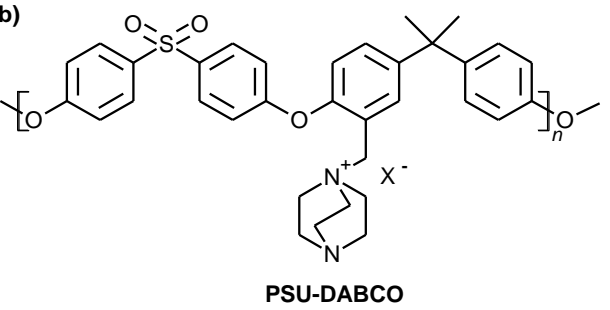

d)

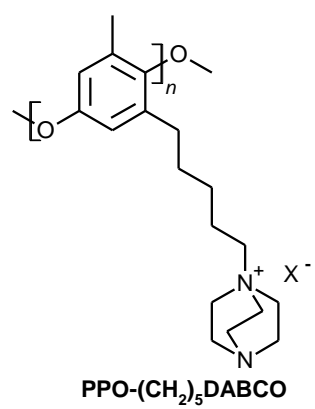

Figure 1. Chemical formulas of a) PSU-TMA, b) PSU-DABCO, c) PPO-DABCO, and d) PPO-DABCO with long side-chain.

8 
Table 1. Ion exchange capacity (IEC), water uptake (WU), and ionic conductivity $(\sigma)$ of various PSU and PPO-based ionomers at $25^{\circ} \mathrm{C}$.

\begin{tabular}{|c|c|c|c|c|c|c|c|}
\hline Samples & $\begin{array}{l}\text { IEC } \\
(\mathrm{meq} / \mathrm{g})\end{array}$ & $\begin{array}{l}\text { WU } \\
(\%)\end{array}$ & $\begin{array}{l}\boldsymbol{\sigma} \\
(\mathrm{mS} / \mathrm{cm})\end{array}$ & Samples & $\begin{array}{l}\text { IEC } \\
(\mathrm{meq} / \mathrm{g})\end{array}$ & $\begin{array}{l}\mathbf{W U} \\
(\%)\end{array}$ & $\begin{array}{l}\boldsymbol{\sigma} \\
(\mathrm{mS} / \mathrm{cm})\end{array}$ \\
\hline \multicolumn{4}{|c|}{ PSU-based AEM (OH form) } & \multicolumn{4}{|c|}{ PPO-based AEM ( $\mathrm{Cl}^{-}$form) } \\
\hline $\mathrm{DABCO}[43]$ & 1.10 & 33.0 & 5.3 & $\mathrm{DABCO}$ & 0.88 & 15.7 & 0.5 \\
\hline DABCO [46] & 1.25 & 85.0 & 5.1 & $\mathrm{DABCO}$ & 0.91 & 22.1 & 0.9 \\
\hline DABCO [47] & 1.57 & 124.3 & 5.3 & DABCO & 1.10 & 22.8 & 1.1 \\
\hline $\mathrm{DABCO}[43]$ & 1.70 & 504.0 & 6.7 & $\mathrm{DABCO}$ & 1.48 & 30.4 & 1.2 \\
\hline $\mathrm{DABCO}-\mathrm{TiO}_{2}[46]$ & 1.25 & 56.0 & 4.3 & $\mathrm{DABCO}$ & 1.60 & 30.6 & 2.0 \\
\hline DABCO-LDH [47] & 1.57 & 25.4 & 2.2 & DABCO long chain [44] & 1.30 & 21.0 & 1.4 \\
\hline TMA [43] & 0.81 & 19.0 & 2.2 & DABCO-LDH & 0.91 & 39.5 & 0.9 \\
\hline TMA 5\% XL* $[43]$ & 0.81 & 26.0 & 2.3 & DABCO-LDH & 1.67 & 36.4 & 1.0 \\
\hline TMA 5\% XL** [43] & 1.19 & 32.0 & 2.2 & DABCO-LDH & 1.69 & 39.8 & 1.3 \\
\hline TMA 5\% XL $* * *[43]$ & 1.19 & 319.0 & 4.3 & & & & \\
\hline TMA [43] & 1.34 & 40.0 & 4.6 & \multicolumn{4}{|c|}{ PSU-based AEM ( ${ }^{-}$form) } \\
\hline TMA [43] & 1.64 & 53.0 & 12.0 & $\mathrm{DABCO}\left(\mathrm{F}^{-}\right.$form $)[50]$ & 1.30 & 198.0 & 5.8 \\
\hline TMA-LDH [47] & 1.67 & 42.1 & 3.7 & TMA (F- form) [50] & 1.64 & 130.0 & 9.5 \\
\hline
\end{tabular}

Table 2. Ion exchange capacity (IEC), water uptake (WU), and hydroxide ion conductivity $(\sigma)$ of PSU-based ionomers at $60{ }^{\circ} \mathrm{C}$ and various relative humidity values (RH) [47].

\begin{tabular}{lllll}
\hline Samples & $\begin{array}{l}\text { IEC } \\
(\mathrm{meq} / \mathrm{g})\end{array}$ & $\begin{array}{l}\text { RH } \\
(\%)\end{array}$ & $\begin{array}{l}\text { WU } \\
(\%)\end{array}$ & $\begin{array}{l}\boldsymbol{\sigma} \\
(\mathrm{mS} / \mathrm{cm})\end{array}$ \\
\hline TMA & 1.67 & 95 & 40.0 & 81.0 \\
& & 80 & 36.1 & 49.6 \\
TMA-LDH & & 65 & 33.1 & 28.0 \\
& 1.67 & 95 & 26.2 & 26.6 \\
& & 80 & 22.8 & 14.7 \\
DABCO & & 65 & 17.7 & 7.4 \\
& 1.57 & 95 & 34.8 & 45.7 \\
& & 80 & 29.1 & 23.0 \\
DABCO-LDH & & 65 & 25.7 & 8.9 \\
& 1.57 & 95 & 28.0 & 30.0 \\
& & 80 & 25.1 & 17.9 \\
& & 65 & 19.8 & 5.5 \\
\hline
\end{tabular}




\section{Discussion}

The ion concentration in the electrolytic solution inside the ionomer channels, expressed in $\mathrm{mol} / \mathrm{L}$, can be calculated from $I E C$ and $W U$ (combining eq. 2-4). $c(i)$ is directly related to the hydration number $\lambda$ (cf. eq. 5):

$$
c(i)=\frac{I E C}{W U}=\frac{1000}{\lambda \cdot M\left(H_{2} O\right)}
$$

Changes of the ion concentration due to an incomplete dissociation or the formation of ion pairs are observed in the effective ion mobility defined by eq. 1.

Figure 2 shows a semi-logarithmic plot of the effective ion mobility at $25{ }^{\circ} \mathrm{C} v s$ the square root of concentration for hydroxide and fluoride ions in PSU-TMA and PSU-DABCO ionomers (triangles) as well as chloride ions in PPO-DABCO based ionomers (dots). Figure 3 shows a comparison of hydroxide ion mobilities in PSU-QA ionomers at 25 and $60{ }^{\circ} \mathrm{C}$ with literature data for proton-conducting SPEEK [31]. We present the data for PSU-DABCO and PSU-TMA with identical symbols in Fig. 3, because there is no significant difference between the two data sets, confirming that the nature of the amine is less important for the anion mobility, as already stated [43].

One should mention that the hydroxide ion mobilities at $60{ }^{\circ} \mathrm{C}$ (calculated from the data in Table 2) were obtained by in-plane measurements $[47,51,52]$, which give somewhat higher ionic conductivities, due to a surface segregation of functional groups [51]. Literature values for the activation energy of hydroxide ion migration are between $0.1-0.2 \mathrm{eV}$ [53-56], but above $0.2 \mathrm{eV}$ for $\lambda<20$ [35].

This $\mathrm{u}(\mathrm{i})$ vs. $\mathrm{c}(\mathrm{i})^{1 / 2}$ plot type is selected following the classical square root concentration dependence of the equivalent conductivity of electrolyte solutions ("Kohlrausch law" [57-59]). A linear decrease with the square root of concentration is observed for strong electrolytes. In "weak" electrolytes, the concentration dependence of the equivalent conductivity is much stronger, due to the incomplete dissociation, which becomes complete only at infinite dilution $[36,58]$. Polyelectrolyte solutions also do not obey the linear limiting law, which is attributed to the high charge density of the polyions and to the flexibility of the polyion chain and its ability to change conformation [60]. A similar strong concentration dependence is here observed for the electrolyte solutions inside ionomers, including those containing strong sulfonic acids, such as SPEEK (Figure 2) and Nafion [30, 34]. The very 
particular boundary conditions experienced by the mobile ions, migrating in close vicinity to the fixed opposite charges of the grafted ionic groups placed at the interfaces between polymer domains and electrolyte solution, leads to a strong concentration dependence of the effective ion mobility. It reflects the concentration-dependent formation of ion pairs or complexes of several ions that break apart only at high water content [35].

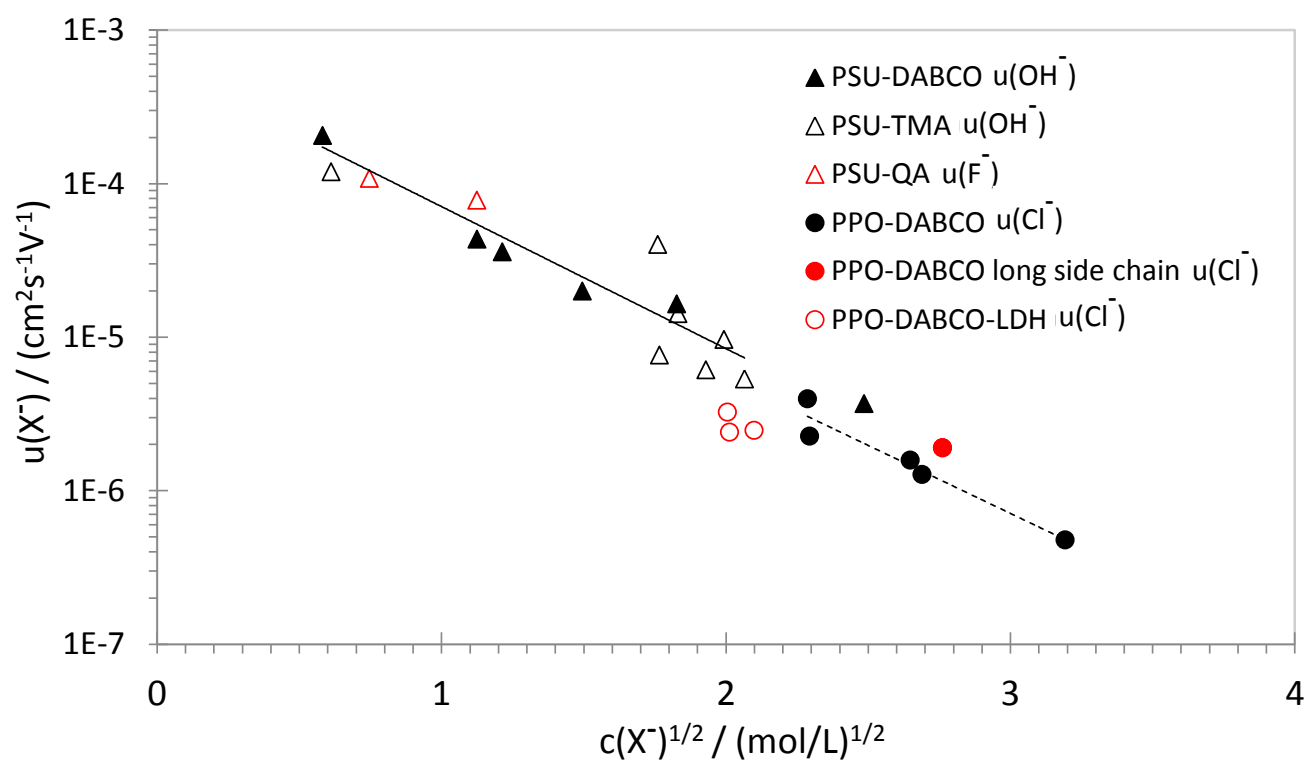

Figure 2. Concentration dependence of the effective mobility of hydroxide and fluoride anions in PSU-based ionomers and chloride anions in PPO-based ionomers with quaternary ammonium groups.

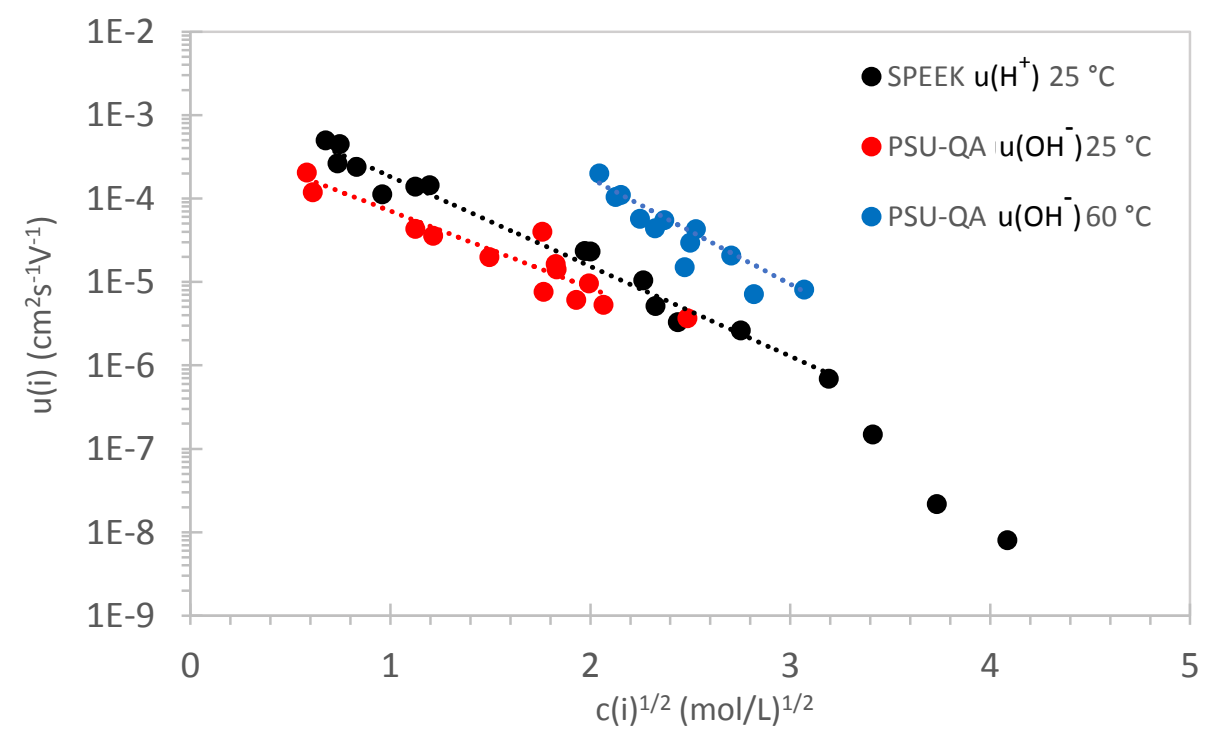

Figure 3. Square root concentration dependence of the effective mobility of hydroxide anions in PSU-based ionomers with quaternary ammonium groups at 25 and $60{ }^{\circ} \mathrm{C}$ and a comparison with the proton mobility in SPEEK from reference [31]. 


\subsection{Porosity and tortuosity}

The ratio of porosity and tortuosity can be determined from the renormalisation equation $7[17,31,34,61]$, where $u(i)^{\circ}$ is the ion mobility at infinite dilution in an aqueous solution not contained in the ionomer matrix.

$u(i)=\frac{\pi}{\tau} \cdot u(i)^{\circ}$

The proton, hydroxide and chloride ion mobility data at $25{ }^{\circ} \mathrm{C}$ are used to extrapolate the ion mobility at infinite dilution, which can be compared with reference literature data. Consistent values for $\mathrm{H}^{+}\left(36.210^{-4} \mathrm{~cm}^{2} \mathrm{~s}^{-1} \mathrm{~V}^{-1}\right), \mathrm{OH}^{-}\left(20.510^{-4} \mathrm{~cm}^{2} \mathrm{~s}^{-1} \mathrm{~V}^{-1}\right)$, and $\mathrm{Cl}^{-}\left(7.910^{-4} \mathrm{~cm}^{2} \mathrm{~s}^{-1} \mathrm{~V}^{-1}\right)$ can be taken from various references [57, 58, 62, 63]. Let us recall that although strong ion pairs are formed in AEM, they are totally dissociated at infinite dilution.

Equation 7 is applied to deduce the ratio porosity/tortuosity from Figure 2 for PSUQA $(\pi / \tau=0.29)$ and PPO-QA $(\pi / \tau=0.38)$ and from Figure 3 for sulfonated poly(ether ether ketone) (SPEEK, $\pi / \tau=0.61)$. Sulfonated aromatic polymers, such as SPEEK, present a lower hydrophilic/hydrophobic nanophase separation than Nafion [22, 64, 65]; two reasons for this difference are that the sulfonic group has a lower acidity and hydrophilicity than the strongly acidic perflurosulfonic group and that the aromatic backbone is less hydrophobic than the perfluorinated polymer backbone (it contains e.g. ether linkages). Other factors, such as chain flexibility, entanglement defects, crystallinity, and the various interaction parameters affect the nanophase separation. AEM with quaternary ammonium groups present an even lower nanophase separation, because the functional groups are less hydrophilic than sulfonic acids $[35,66]$. The lower $\pi / \tau$ values for PSU-QA and PPO-QA are consistent with a lower hydrophilic-hydrophobic nanophase separation, which leads to channels with low diameter (low $\pi$ ) and high tortuosity $\tau$ (for example more dead-ends [8]). The lowest value for PSUQA corresponds to the larger hydrophilicity of the PSU backbone vs. PPO, due inter alia to the presence of sulfone groups, which further reduces the nanophase separation and the porosity/tortuosity ratio, leading to narrower hydrophilic channels and to a larger separation between the functional groups [67].

Phenomenological relations exist between porosity and tortuosity; the best known is the Bruggeman-type expression [61]:

$\tau=\pi^{-(\alpha-1)}$

$\alpha$ is the universal percolation exponent [30, 68]. Assuming three-dimensional percolation ( $\alpha$ $\approx 2$ ), one obtains a tortuosity of 1.9 for PSU-QA and 1.6 for PPO-QA, in good agreement 
with the values reported for PSU-QA $(\tau=1.83-1.88$ [36]) and for a PPO-based copolymer $(\tau$ $=1.8[56])$.

\subsection{Percolation}

The ionic conductivity can be written near and above the percolation threshold as a function of the volume fraction of the hydrated domains $\phi_{\mathrm{H}_{2} \mathrm{O}}[18,69]$ :

$\sigma(i)=\sigma(i)^{\circ} \cdot\left(\phi_{\mathrm{H}_{2} \mathrm{O}}-\phi_{\mathrm{H}_{2} \mathrm{O}, \mathrm{p}}\right)^{\alpha}$

The universal percolation exponent $\alpha$ is near 2 for three-dimensional (3D) percolation [30, 68]. $\phi_{\mathrm{H}_{2} \mathrm{O}, p}$ is the water volume fraction at the percolation threshold and $\sigma(i)^{\circ}$ is the prefactor. By simple mathematical transformation of eq. 9, one can show that a plot $\sigma(i)^{1 / 2}=f\left(\phi_{\mathrm{H}_{2} \mathrm{O}}\right)$ should give a straight line; $\sigma(i)^{\circ}$ and $\phi_{\mathrm{H}_{2} \mathrm{O}, p}$ can be determined from its slope and intercept, respectively.

The volume fraction of water $\phi_{\mathrm{H}_{2} \mathrm{O}}$ in the wet ionomer is defined and related to WU (cf. eq. 3 ) by eq. 10 :

$\phi_{\mathrm{H}_{2} \mathrm{O}}=\frac{V_{\mathrm{H}_{2} \mathrm{O}}}{V_{\mathrm{H}_{2} \mathrm{O}}+V_{d r y}}=\frac{W U \cdot \rho_{d r y}}{1+W U \cdot \rho_{d r y}}$

The volume fraction $\phi_{\mathrm{H}_{2} \mathrm{O}}$ can be related to the IEC and the ion concentration combining eq. 6 and 10:

$\phi_{\mathrm{H}_{2} \mathrm{O}}=\frac{I E C \cdot \rho_{d r y}}{c(i)+I E C \cdot \rho_{d r y}}$

The dry density $\rho_{d r y}$ of the polymers is taken as $2.07 \mathrm{~g} / \mathrm{cm}^{3}$ for Nafion [14], $1.34 \mathrm{~g} / \mathrm{cm}^{3}$ for SPEEK [70], or by the values for PPO $\left(1.06 \mathrm{~g} / \mathrm{cm}^{3}\right.$ [71]) and PSU (1.24 g/ $/ \mathrm{cm}^{3}$ [72]). Using experimental values for each membrane might further improve the quality of the fits. Figure 4 shows such a plot for PSU-TMA and PPO-QA and a comparison with SPEEK [31] and reference data for Nafion [8]. 


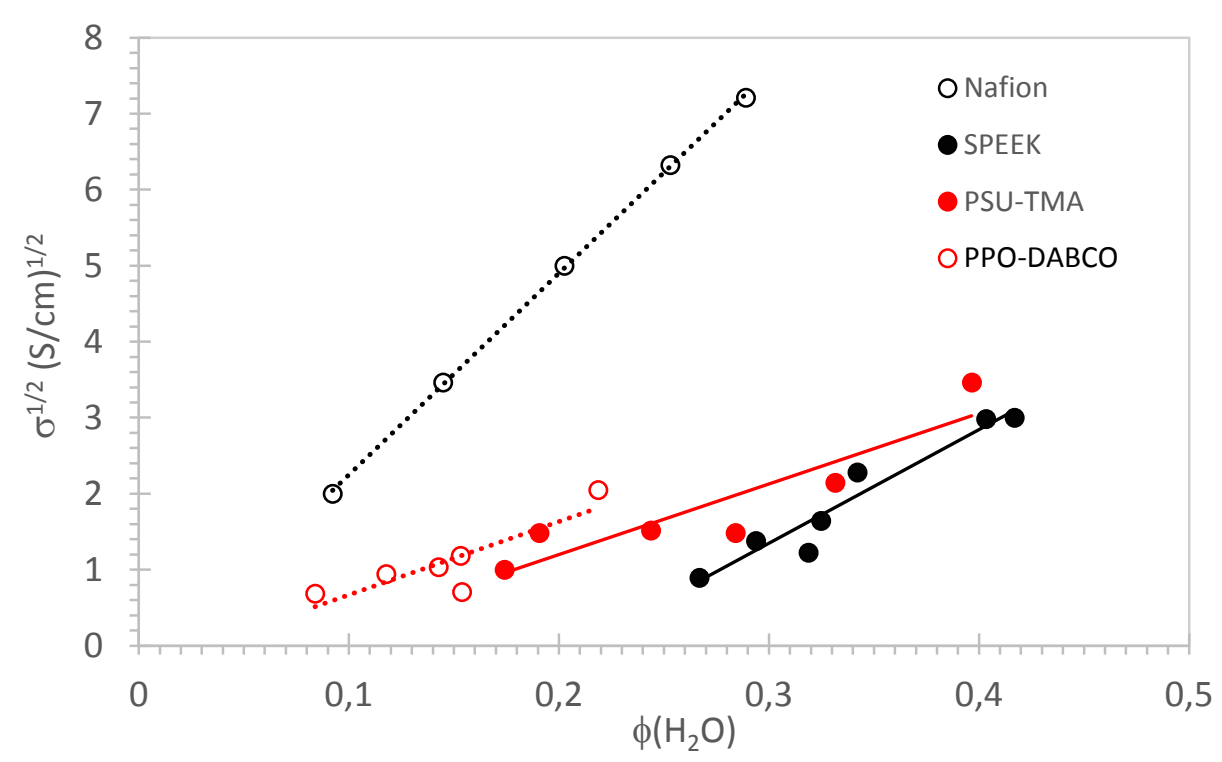

Figure 4. Determination of the percolation threshold for AEM, SPEEK and Nafion.

The percolation threshold $\phi_{\mathrm{H}_{2} \mathrm{O}, p}$ is at a water volume fraction of 0.01 for Nafion and somewhat higher, but not that much for PSU-TMA (0.07) and PPO-DABCO ionomers (0.03), whereas it is much higher for SPEEK (0.21). Indeed, no percolation threshold is observed for PSU-QA in Figure 3, whereas it is clearly visible for SPEEK. The percolation threshold for conduction paths to traverse the ionomer, $\phi_{\mathrm{H}_{2} \mathrm{O}, p}$, is reported in SPEEK at a water volume fraction below 0.3 , consistent with a stochastic medium with randomly dispersed spherical hydrated clusters $[21,61,73,74]$. Pisani et al. fit conductivity data for SPEEK with $\phi_{\mathrm{H}_{2} O, p}=$ 0.22 , in excellent agreement with our result [61]. Lamellar hydrophilic domains, supposed to exist in Nafion, percolate through the hydrophobic matrix at a volume fraction below 0.1 [13, $18,73,74]$, which is much lower than the value for a completely random system. Pisani et al. take $\phi_{H_{2} O, p}=0$ for the simulation of Nafion conductivity data [61].

The low percolation threshold value for PSU-TMA and PPO-DABCO (well below 0.1, like that reported for PEEK-QA [37]) seems to indicate that these AEM present also a partly two-dimensional (2D) structure of the hydrated domains, but less pronounced than Nafion ("layered morphologies" [75]). Indeed, SAXS investigations suggested nanometerrange swelling to occur in two dimensions in AEM with polymer chains having a tendency to arrange locally in a parallel fashion [35]. Mesoscale simulations support this picture of layered morphology [39]. The particularly low percolation threshold for PSU-TMA is consistent with the low nanophase separation in PSU-QA (see above), which leads to narrower hydrophilic channels than in PPO-QA. It is well known that percolation thresholds 
are displaced to lower volume fractions, when the domain size of the percolating phase decreases (correlation effects) [76, 77].

The prefactor $\sigma(i)^{\circ}$ represents mathematically the ionic conductivity when $\left(\phi_{\mathrm{H}_{2} \mathrm{O}}-\right.$ $\left.\phi_{\mathrm{H}_{2} \mathrm{O}, p}\right)=1$, corresponding to a "bulk" electrolyte experiencing similar electrostatic boundary conditions than in the ionomer. The prefactor $\sigma(i)^{\circ}$ depends on the particular conduction mechanism within and between two adjacent clusters, involving interactions among ions, water molecules, and the ionomer [13]. The prefactor should therefore represent a good indication as to the maximum achievable ionic conductivity in an ionomer. Indeed, $\sigma(i)^{\circ}$ is much higher for Nafion $(\sim 700 \mathrm{mS} / \mathrm{cm})$ and SPEEK $(223 \mathrm{mS} / \mathrm{cm})$ than for PSU-TMA $(86 \mathrm{mS} / \mathrm{cm})$ and PPO-DABCO $(93 \mathrm{mS} / \mathrm{cm})$ in good accordance with the larger mobility of protons vs. hydroxide ions and the larger tortuosity of AEM.

\subsection{Hydration dependence of the ionic conductivity}

The presence of a solvent with high dielectric constant, especially water, is fundamental for the particular conduction mechanism in ionomers. However, hydration has antagonistic effects on the conductivity, because a large hydration increases the effective ion mobility, but reduces the ion concentration.

Figure 5 shows a plot of the proton, hydroxide and chloride ion conductivity in ionomers as function of the hydration number. The dots correspond to experimental data from Tables 1 and 2 or reference [31] for SPEEK. The lines are computed from the ion concentrations and effective ion mobilities. These plots show a maximum ionic conductivity for an intermediate value of the hydration number, corresponding to optimal hydration conditions, around 60 for AEM and 80 for SPEEK. The maximum conductivities are still significantly below the prefactors obtained from the percolation approach above, indicating that there is still substantial room for improvement of the ionic conductivity of these ionomers. 


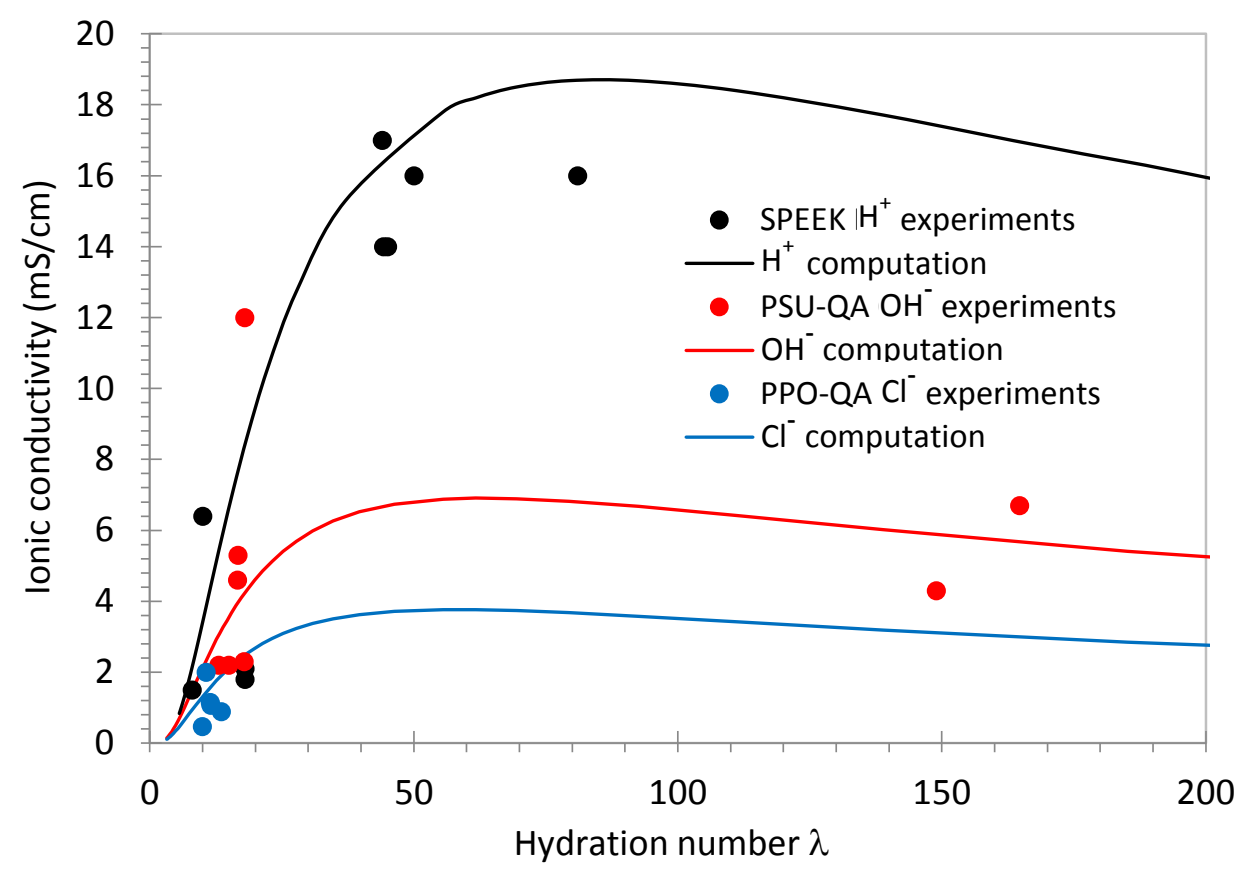

Figure 5. Experimental and computed ionic conductivity dependence on the hydration number for protons [31], hydroxide and chloride ion-conducing ionomers at $25^{\circ} \mathrm{C}$.

For large hydration numbers, the aqueous channels are fully percolating and the sulfonic acid groups are fully dissociated, but the ion pairs in AEM not necessarily, so that the ion concentration calculated according to eq. 6 is overestimated and the effective mobility calculated is underestimated according to eq. 1 . At $\lambda=100$, the ratio of conductivity for SPEEK and PPO-QA amounts to 4.6, whereas the mobility ratio at infinite dilution is 5.3 [57, 58]. Assuming that this difference is related only to the incomplete dissociation of ion pairs in PPO-QA would lead to a dissociation degree of $85 \%$ for $\mathrm{Cl}^{-}$ions. This value is somewhat higher than the values of around 50\% reported by Kreuer et al. for the $\mathrm{Cl}^{-}$dissociation in a related AEM [35]. Laidler et al. reported a dissociation constant of 28 for tetramethylammonium iodide in acetone solution that would give similar dissociation degrees [78]. However, there are two major differences with AEM, which have an antagonistic effect on ion pair dissociation: the solvent acetone has a low dielectric constant, but the acetone solution is not contained in an ionomer with its very particular electrostatic situation.

Finally, making a similar comparison of the conductivity ratio of PSU-QA $\left(\mathrm{OH}^{-}\right)$and PPO-QA $\left(\mathrm{Cl}^{-}\right)$, which is 1.8 at $\lambda=100$, and the ratio of the ion mobility of hydroxide and chloride ions at infinite dilution $(2.6[57,58])$, the difference might again be attributed to the 
different dissociation degree of ion pairs indicating that the degree of dissociation of ion pairs would be about $30 \%$ lower for hydroxide than for chloride ions. This result is consistent with the effective ionic radii of chloride (181 pm [79]) and hydroxide ions (132 pm [79]) given that a lower ion radius increases the strength of ion pairs [80-82].

\section{Conclusions}

The effective ion mobility in ionomers is a key property in order to reach ionic conductivities high enough to design ionomer separators for electrochemical devices with low area specific resistance. The effective ion mobility is a complex parameter, which depends on the complicated situation encountered by the mobile ions during their migration in the restricted area of ion conduction channels surrounded by a solvent with high dielectric constant and fixed counter-ions grafted on the channel walls. This complexity can be described by several phenomenological parameters, such as porosity and tortuosity, percolation threshold, degree of dissociation of ion pairs.

In this work, we determined and analysed the effective anion mobility in various anion exchange membranes with PSU or PPO backbones. Linear semi-logarithmic plots of the effective ion mobility vs. the square root of the ion concentration allowed determining the ratio porosity/tortuosity. The values of AEM (PSU-QA: $\pi / \tau=0.29$ and PPO-QA: $\pi / \tau=0.38$ ) are inferior to those of proton exchange membranes (SPEEK, $\pi / \tau=0.61$ ). This finding can be attributed to a lower nanophase separation, due to the minor hydrophilicity of quaternary ammonium groups vs sulfonic acids. The smaller value for PSU-QA with respect to PPO-QA is related to the lower hydrophobicity of the ionomer backbone, due to the more hydrophilic sulfone moieties and the absence of methyl groups.

The percolation threshold was determined from linear plots of the square root of ionic conductivity vs. the volume fraction of aqueous domains. The low percolation threshold of AEM (PSU-TMA: $\phi_{\mathrm{H}_{2} O, p}=0.07$ and PPO-QA: $\phi_{\mathrm{H}_{2} \mathrm{O}, p}=0.03$ ) indicates the existence of $2 \mathrm{D}$ arrangements of the ionic domains, which percolate at lower water fractions than $3 \mathrm{D}$ domains. This finding is in agreement with the conclusions of literature SAXS experiments.

The ion conductivity shows a maximum for a hydration number around 60 for AEM, which corresponds to an optimal compromise of anion concentration and effective anion mobility. The ratio of conductivities for chloride and hydroxide ions indicates that the degree of dissociation of ion pairs is about $30 \%$ lower for $\mathrm{OH}^{-}$ions. This conclusion is consistent 
with the lower radius of hydroxide ions, because the strength of ion pairs, due to Coulombic interactions, is related to the inter-ionic distance.

\section{References}

[1] J.R. Varcoe, P. Atanassov, D.R. Dekel, A.M. Herring, M.A. Hickner, P.A. Kohl, A.R. Kucernak, W.E. Mustain, K. Nijmeijer, K. Scott, T.W. Xu, L. Zhuang, Anion-exchange membranes in electrochemical energy systems, Energy \& Environmental Science 7(10) (2014) 3135-3191.

[2] K.D. Kreuer, Ion Conducting Membranes for Fuel Cells and other Electrochemical Devices, Chemistry of Materials 26(1) (2014) 361-380.

[3] B. Smitha, S. Sridhar, A.A. Khan, Solid polymer electrolyte membranes for fuel cell applications a review, Journal of Membrane Science 259(1-2) (2005) 10-26.

[4] T.N.L. Doan, T.K.A. Hoang, P. Chen, Recent development of polymer membranes as separators for all-vanadium redox flow batteries, Rsc Advances 5(89) (2015) 72805-72815.

[5] D.R. Dekel, Review of cell performance in anion exchange membrane fuel cells, Journal of Power Sources 375 (2018) 158-169.

[6] S. Gottesfeld, D.R. Dekel, M. Page, C. Bae, Y.S. Yan, P. Zelenay, Y.S. Kim, Anion exchange membrane fuel cells: Current status and remaining challenges, Journal of Power Sources 375 (2018) $170-184$.

[7] K.D. Kreuer, On the development of proton conducting polymer membranes for hydrogen and methanol fuel cells, Journal of Membrane Science 185(1) (2001) 29-39.

[8] K.D. Kreuer, S.J. Paddison, E. Spohr, M. Schuster, Transport in proton conductors for fuel-cell applications: Simulations, elementary reactions, and phenomenology, Chemical Reviews 104(10) (2004) 4637-4678.

[9] B. Bauer, H. Strathmann, F. Effenberger, Anion-Exchange Membranes with Improved Alkaline Stability, Desalination 79(2-3) (1990) 125-144.

[10] T.J. Peckham, J. Schmeisser, M. Rodgers, S. Holdcroft, Main-chain, statistically sulfonated proton exchange membranes: the relationships of acid concentration and proton mobility to water content and their effect upon proton conductivity, Journal of Materials Chemistry 17(30) (2007) 32693269.

[11] K.D. Kreuer, On the development of proton conducting materials for technological applications, Solid State Ionics 97(1-4) (1997) 1-15.

[12] T.A. Zawodzinski, C. Derouin, S. Radzinski, R.J. Sherman, V.T. Smith, T.E. Springer, S. Gottesfeld, Water-Uptake by and Transport Through Nafion 117 Membranes, Journal of the Electrochemical Society 140(4) (1993) 1041-1047.

[13] K.A. Mauritz, R.B. Moore, State of understanding of Nafion, Chemical Reviews 104(10) (2004) 4535-4585.

[14] T.D. Gierke, G.E. Munn, F.C. Wilson, THE MORPHOLOGY IN NAFION PERFLUORINATED MEMBRANE PRODUCTS, AS DETERMINED BY WIDE-ANGLE AND SMALL-ANGLE X-RAY STUDIES, Journal of Polymer Science Part B-Polymer Physics 19(11) (1981) 1687-1704.

[15] H.L. Yeager, A. Steck, Cation and water diffusion in nafion ion-exchange membranes - influence of polymer structure, Journal of the Electrochemical Society 128(9) (1981) 1880-1884.

[16] N. Epstein, On tortuosity and the tortuosity factor in flow and diffusion through porous-media, Chemical Engineering Science 44(3) (1989) 777-779.

[17] V. Wernert, R. Bouchet, R. Denoyel, Influence of Molecule Size on Its Transport Properties through a Porous Medium, Analytical Chemistry 82(7) (2010) 2668-2679.

[18] W.Y. Hsu, J.R. Barkley, P. Meakin, ION PERCOLATION AND INSULATOR-TOCONDUCTOR TRANSITION IN NAFION PERFLUOROSULFONIC ACID MEMBRANES, Macromolecules 13(1) (1980) 198-200.

[19] O. Diat, G. Gebel, Proton channels, Nature Materials 7(1) (2008) 13-14.

[20] G. Gebel, Structural evolution of water swollen perfluorosulfonated ionomers from dry membrane to solution, Polymer 41(15) (2000) 5829-5838. 
[21] G. Gebel, Structure of Membranes for Fuel Cells: SANS and SAXS Analyses of Sulfonated PEEK Membranes and Solutions, Macromolecules 46(15) (2013) 6057-6066.

[22] T.J. Peckham, J. Schmeissert, S. Holdcroft, Relationships of acid and water content to proton transport in statistically sulfonated proton exchange membranes: Variation of water content via control of relative humidity, Journal of Physical Chemistry B 112(10) (2008) 2848-2858.

[23] P.J. Flory, J. Rehner, Statistical mechanics of cross-linked polymer networks II Swelling, Journal of Chemical Physics 11(11) (1943) 521-526.

[24] A. Telfah, G. Majer, K.D. Kreuer, M. Schuster, J. Maier, Formation and mobility of protonic charge carriers in methyl sulfonic acid-water mixtures: A model for sulfonic acid based ionomers at low degree of hydration, Solid State Ionics 181(11-12) (2010) 461-465.

[25] T.A. Zawodzinski, T.E. Springer, J. Davey, R. Jestel, C. Lopez, J. Valerio, S. Gottesfeld, A Comparative Study of Water-Uptake by and Transport Through Ionomeric Fuel-Cell Membranes, Journal of the Electrochemical Society 140(7) (1993) 1981-1985.

[26] S.J. Paddison, The modeling of molecular structure and ion transport in sulfonic acid based ionomer membranes, Journal of New Materials for Electrochemical Systems 4(4) (2001) 197-207.

[27] S.J. Paddison, R. Paul, The nature of proton transport in fully hydrated Nafion (R), Physical Chemistry Chemical Physics 4(7) (2002) 1158-1163.

[28] S.J. Paddison, R. Paul, K.D. Kreuer, Theoretically computed proton diffusion coefficients in hydrated PEEKK membranes, Physical Chemistry Chemical Physics 4(7) (2002) 1151-1157.

[29] M.A. Hickner, Water-mediated transport in ion-containing polymers, Journal of Polymer Science Part B-Polymer Physics 50(1) (2012) 9-20.

[30] P. Knauth, E. Sgreccia, A. Donnadio, M. Casciola, M.L. Di Vona, Water Activity Coefficient and Proton Mobility in Hydrated Acidic Polymers, Journal of the Electrochemical Society 158(2) (2011) B159-B165.

[31] M.L. Di Vona, L. Pasquini, R. Narducci, K. Pelzer, A. Donnadio, M. Casciola, P. Knauth, Crosslinked sulfonated aromatic ionomers via SO2 bridges: Conductivity properties, Journal of Power Sources 243 (2013) 488-493.

[32] P. Knauth, L. Pasquini, B. Maranesi, K. Pelzer, R. Polini, M.L. Di Vona, Proton Mobility in Sulfonated PolyEtherEtherKetone (SPEEK): Influence of Thermal Crosslinking and Annealing, Fuel Cells 13(1) (2013) 79-85.

[33] M.L. Di Vona, S. Licoccia, P. Knauth, Organic-inorganic hybrid membranes based on sulfonated polyaryl-ether-ketones: Correlation between water uptake and electrical conductivity, Solid State Ionics 179(21-26) (2008) 1161-1165.

[34] P. Knauth, M.L. Di Vona, Sulfonated aromatic ionomers: Analysis of proton conductivity and proton mobility, Solid State Ionics 225 (2012) 255-259.

[35] M.G. Marino, J.P. Melchior, A. Wohlfarth, K.D. Kreuer, Hydroxide, halide and water transport in a model anion exchange membrane, Journal of Membrane Science 464 (2014) 61-71.

[36] A. Amel, N. Gavish, L. Zhu, D.R. Dekel, M.A. Hickner, Y. Ein-Eli, Bicarbonate and chloride anion transport in anion exchange membranes, Journal of Membrane Science 514 (2016) 125-134.

[37] X.M. Yan, G.H. He, X.M. Wu, J. Benziger, Ion and water transport in functionalized PEEK membranes, Journal of Membrane Science 429 (2013) 13-22.

[38] M.L. Disabb-Miller, Z.D. Johnson, M.A. Hickner, Ion Motion in Anion and Proton-Conducting Triblock Copolymers, Macromolecules 46(3) (2013) 949-956.

[39] F. Sepehr, H.J. Liu, X.B. Luo, C.S. Bae, M.E. Tuckerman, M.A. Hicknee, S.J. Paddison, Mesoscale Simulations of Anion Exchange Membranes Based on Quaternary Ammonium Tethered Triblock Copolymers, Macromolecules 50(11) (2017) 4397-4405.

[40] X.M. Wu, W.T. Chen, X.M. Yan, G.H. He, J.J. Wang, Y. Zhang, X.P. Zhu, Enhancement of hydroxide conductivity by the di-quaternization strategy for poly(ether ether ketone) based anion exchange membranes, Journal of Materials Chemistry A 2(31) (2014) 12222-12231.

[41] N.A. Stolwijk, M. Wiencierz, C. Heddier, J. Kosters, What Can We Learn from Ionic Conductivity Measurements in Polymer Electrolytes? A Case Study on Poly(ethylene oxide) (PEO)NaI and PEO-LiTFSI, Journal of Physical Chemistry B 116(10) (2012) 3065-3074.

[42] G.S. Manning, Counterion binding in polyelectrolyte theory, Accounts of Chemical Research 12(12) (1979) 443-449. 
[43] M.L. Di Vona, R. Narducci, L. Pasquini, K. Pelzer, P. Knauth, Anion-conducting ionomers: Study of type of functionalizing amine and macromolecular cross-linking, International Journal of Hydrogen Energy 39(26) (2014) 14039-14049.

[44] R.A. Becerra-Arciniegas, R. Narducci, G. Ercolani, E. Sgreccia, L. Pasquin, M.L. Di Vona, P. Knauth, Model Long Side-Chain PPO-Based Anion Exchange Ionomers: Properties and Alkaline Stability, Journal of Physical Chemistry C 124(2) (2020) 1309-1316.

[45] R.A. Becerra-Arciniegas, R. Narducci, G. Ercolani, S. Antonaroli, E. Sgreccia, L. Pasquini, P. Knauth, M.L. Di Vona, Alkaline stability of model anion exchange membranes based on poly (phenylene oxide) (PPO) with grafted quaternary ammonium groups: Influence of the functionalization route, Polymer 185 (2019).

[46] Z. Derbali, A. Fahs, J.F. Chailan, I.V. Ferrari, M.L. Di Vona, P. Knauth, Composite anion exchange membranes with functionalized hydrophilic or hydrophobic titanium dioxide, International Journal of Hydrogen Energy 42(30) (2017) 19178-19189.

[47] M.L. Di Vona, M. Casciola, A. Donnadio, M. Nocchetti, L. Pasquini, R. Narducci, P. Knauth, Anionic conducting composite membranes based on aromatic polymer and layered double hydroxides, International Journal of Hydrogen Energy 42(5) (2017) 3197-3205.

[48] R. Pizzoferrato, E. Ciotta, I.V. Ferrari, R. Narducci, L. Pasquini, A. Varone, M. Richetta, S. Antonaroli, M. Braglia, P. Knauth, M.L. Di Vona, Layered Double Hydroxides Containing an Ionic Liquid: Ionic Conductivity and Use in Composite Anion Exchange Membranes, Chemelectrochem 5(19) (2018) 2781-2788.

[49] G. Alberti, M.L. Di Vona, R. Narducci, New results on the visco-elastic behaviour of ionomer membranes and relations between T-RH plots and proton conductivity decay of Nafion (R) 117 in the range 50-140 degrees C, International Journal of Hydrogen Energy 37(7) (2012) 6302-6307.

[50] L. Pasquini, F. Ziarelli, S. Viel, M.L. Di Vona, P. Knauth, Fluoride-ion-conducting Polymers: Ionic Conductivity and Fluoride Ion Diffusion Coefficient in Quaternized Polysulfones, Chemphyschem 16(17) (2015) 3631-3636.

[51] M. Casciola, A. Donnadio, P. Sassi, A critical investigation of the effect of hygrothermal cycling on hydration and in-plane/through-plane proton conductivity of Nafion 117 at medium temperature (70-130 degrees C), Journal of Power Sources 235 (2013) 129-134.

[52] M. Casciola, G. Alberti, M. Sganappa, R. Narducci, On the decay of Nafion proton conductivity at high temperature and relative humidity, Journal of Power Sources 162(1) (2006) 141-145.

[53] M.E. Tuckerman, D. Marx, M. Parrinello, The nature and transport mechanism of hydrated hydroxide ions in aqueous solution, Nature 417(6892) (2002) 925-929.

[54] N. Agmon, Mechanism of hydroxide mobility, Chemical Physics Letters 319(3-4) (2000) $247-$ 252.

[55] D. Marx, A. Chandra, M.E. Tuckerman, Aqueous Basic Solutions: Hydroxide Solvation, Structural Diffusion, and Comparison to the Hydrated Proton, Chemical Reviews 110(4) (2010) 2174 2216.

[56] T.P. Pandey, H.N. Sarode, Y.T. Yang, Y. Yang, K. Vezzu, V. Di Noto, S. Seifert, D.M. Knauss, M.W. Liberatore, A.M. Herring, A Highly Hydroxide Conductive, Chemically Stable Anion Exchange Membrane, Poly(2,6 dimethyl 1,4 phenylene oxide)-b-Poly(vinyl benzyl trimethyl ammonium), for Electrochemical Applications, Journal of the Electrochemical Society 163(7) (2016) H513-H520.

[57] G. Kortüm, Treatise on Electrochemistry, 2nd edition, 2nd ed., Elsevier, Amsterdam, New York, 1965.

[58] C.H. Hamann, A. Hamnett, W. Vielstich, Electrochemistry, 2nd Edition ed., Wiley-VCH, Weinheim, 2007.

[59] L. Onsager, The motion of ions: principles and concepts, Science (New York, N.Y.) 166(3911) (1969) 1359-64.

[60] J. M'Halla, S. Boughammoura, A. Ghazouani, Some New Contributions to the Theory of Polyelectrolyte Solutions: Prediction of Polyion Conformation and Interpretation of Some Deviations from Kohlrausch's Law According to the Superposition Principle and the Dielectric Friction Effect, Journal of Solution Chemistry 48(11-12) (2019) 1685-1715.

[61] L. Pisani, M. Valentini, D.H. Hofmann, L.N. Kuleshova, B. D'Aguanno, An analytical model for the conductivity of polymeric sulfonated membranes, Solid State Ionics 179(13-14) (2008) 465-476. 
[62] G. Milazzo, P.J. Mill, Electrochemistry: Theoretical Principles and Practical Applications, Elsevier, New York1963.

[63] R.C. Weast, Handbook of Chemistry and Physics, CRC Press, Boca Raton, 1981, p. F216.

[64] C.V. Mahajan, V. Ganesan, Atomistic Simulations of Structure of Solvated Sulfonated Poly(ether ether ketone) Membranes and Their Comparisons to Nafion: II. Structure and Transport Properties of Water, Hydronium Ions, and Methanol, Journal of Physical Chemistry B 114(25) (2010) 8367-8373.

[65] C.V. Mahajan, V. Ganesan, Atomistic Simulations of Structure of Solvated Sulfonated Poly(ether ether ketone) Membranes and Their Comparisons to Nafion: I. Nanophase Segregation and Hydrophilic Domains, Journal of Physical Chemistry B 114(25) (2010) 8357-8366.

[66] H.S. Dang, P. Jannasch, Exploring Different Cationic Alkyl Side Chain Designs for Enhanced Alkaline Stability and Hydroxide Ion Conductivity of Anion-Exchange Membranes, Macromolecules 48(16) (2015) 5742-5751.

[67] K.D. Kreuer, G. Portale, A Critical Revision of the Nano-Morphology of Proton Conducting Ionomers and Polyelectrolytes for Fuel Cell Applications, Advanced Functional Materials 23(43) (2013) 5390-5397.

[68] D. Staufer, A. Aharony, Introduction to Percolation Theory, Taylor and Francis, London, 1992.

[69] J.P. Clerc, G. Giraud, J.M. Laugier, J.M. Luck, The ac Electrical Conductivity of Binary

Disordered-Systems, Percolation Clusters, Fractals and Related Models, Advances in Physics 39(3) (1990) 191-308.

[70] R. Narducci, M.L. Di Vona, P. Knauth, Cation-conducting ionomers made by ion exchange of sulfonated poly-ether-ether-ketone: Hydration, mechanical and thermal properties and ionic conductivity, Journal of Membrane Science 465 (2014) 185-192.

[71] M. Liang, Poly(phenylene oxide), in: S. Thomas, P.M. Visakh (Eds.), Handbook of engineering and specialty thermoplastics, Scrivener, Wiley, Salem, MA, Hoboken, NJ, USA, 2011, pp. 15-54. [72] V.R. Sastri, Chapter 8 - High-Temperature Engineering Thermoplastics: Polysulfones, Polyimides, Polysulfides, Polyketones, Liquid Crystalline Polymers, and Fluoropolymers, in: V.R. Sastri (Ed.), Plastics in Medical Devices, William Andrew Publishing, Boston, 2010, pp. 175-215. [73] P.V. Komarov, I.N. Veselov, P.P. Chu, P.G. Khalatur, Mesoscale simulation of polymer electrolyte membranes based on sulfonated poly(ether ether ketone) and Nafion, Soft Matter 6(16) (2010) 3939-3956.

[74] X.M. Wu, X.W. Wang, G.H. He, J. Benziger, Differences in Water Sorption and Proton Conductivity Between Nafion and SPEEK, Journal of Polymer Science Part B-Polymer Physics 49(20) (2011) 1437-1445.

[75] G. Alberti, R. Narducci, M.L. Di Vona, S. Giancola, More on Nafion Conductivity Decay at Temperatures Higher than $80^{\circ} \mathrm{C}$ : Preparation and First Characterization of In-Plane Oriented Layered Morphologies, Industrial \& Engineering Chemistry Research 52(31) (2013) 10418-10424.

[76] J.M. Debierre, P. Knauth, G. Albinet, Enhanced conductivity in ionic conductor-insulator composites: Experiments and numerical model, Applied Physics Letters 71(10) (1997) 1335-1337.

[77] G. Albinet, J.M. Debierre, P. Knauth, C. Lambert, L. Raymond, Enhanced conductivity in ionic conductor-insulator composites: numerical models in two and three dimensions, European Physical Journal B 22(4) (2001) 421-427.

[78] W.A. Adams, K.J. Laidler, Electrical conductivities of quaternary ammonium salts in acetone 1. Pressure and temperature effects, Canadian Journal of Chemistry 46(12) (1968) 1977-\&.

[79] R.D. Shannon, Revised effective ionic-radii and systematic studies of interatomic distances in halides and chalcogenides, Acta Crystallographica Section A 32(SEP1) (1976) 751-767.

[80] L. Onsager, Deviations from Ohm's Law in Weak Electrolytes, Journal of Chemical Physics 2(9) (1934) 17.

[81] W.A. Adams, K.J. Laidler, Electrical Conductivities of Quaternary Ammonium Salts in Acetone 2. Mechanisms of Transport, Canadian Journal of Chemistry 46(12) (1968) 1977-1988.

[82] W.A. Adams, K.J. Laidler, Electrical Conductivities of Quaternary Ammonium Salts in Acetone 3. Ion-Pair Formation, Canadian Journal of Chemistry 46(12) (1968) 2005-2011. 
Graphical abstract

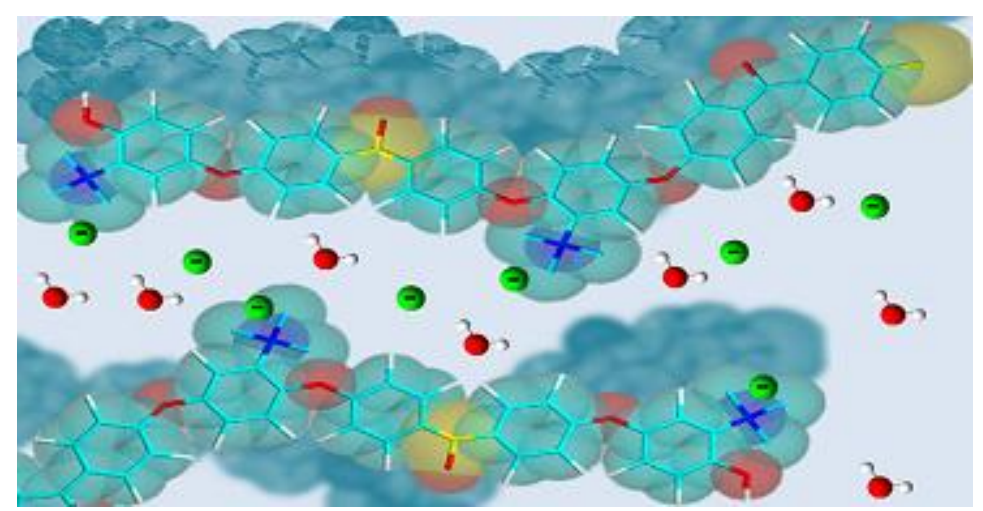

